\title{
Changes in $\mathrm{HbAlc}$, body weight, and systolic blood pressure in type 2 diabetes patients initiating dapagliflozin therapy: a primary care database study
}

\author{
This article was published in the following Dove Press journal: \\ Diabetes, Metabolic Syndrome and Obesity:Targets and Therapy \\ 31 October 2016 \\ Number of times this article has been viewed
}

\section{Markus F Scheerer \\ Roland Rist' \\ Orm Proske' \\ Annika Meng ${ }^{2}$ \\ Karel Kostev ${ }^{2}$}

'Medical Department, AstraZeneca GmbH, Wedel, Germany; ${ }^{2}$ MS Health $\mathrm{GmbH} \& \mathrm{Co}$. OHG, Frankfurt am Main, Germany
Correspondence: Karel Kostev Epidemiology \& Evidence-Based Medicine, Real-World Evidence Solutions, IMS Health GmbH \& Co. OHG, Darmstädter Landstraße 108, 60598 Frankfurt am Main, Germany

Tel +49696604 4878

Email kkostev@de.imshealth.com
Aims: To investigate changes in glycated hemoglobin ( $\mathrm{HbA} 1 \mathrm{c})$, body weight $(\mathrm{BW})$, and systolic blood pressure (SBP) in type 2 diabetes (T2D) primary care patients initiating dapagliflozin treatment. Methods: T2D patients who started dapagliflozin in 985 general and 32 diabetologist practices (Disease Analyzer, Germany: December 2012-October 2014) were analyzed (3- and 6-month follow-up). Multivariate linear regression analyses were used to identify clinical characteristics and comorbidity associated with changes in $\mathrm{HbA1c}, \mathrm{BW}$, and SBP.

Results: The study included 1,169 T2D patients (age: 62.5 years; men: 59.3\%; diabetologist care: $23 \%$ ) with newly initiated dapagliflozin therapy. At the 3-month stage, dapagliflozin significantly reduced $\mathrm{HbAlc}(-0.8 \% \pm 1.4 \%)$ compared to the baseline $(8.5 \% \pm 1.5 \%)(P<0.001)$. Changes were maintained after 6 months $(-0.8 \% \pm 1.5 \%)(P<0.001)$. Patients with high baseline $\mathrm{HbA1c}$ values $(>9 \%)$ showed greater reductions in $\mathrm{HbA} 1 \mathrm{c}$ than the overall sample (3 months $-1.8 \%, 6$ months $-1.8 \%$; both $P<0.05$ ). BW and SBP also showed statistically significant reductions with dapagliflozin over 3 and 6 months $(-2.2 \mathrm{~kg}, P<0.001 ;-2.2 \mathrm{mmHg}, P=0.003$ and $-2.5 \mathrm{~kg}, P<0.001 ;-2.3 \mathrm{mmHg}, P=0.011$, respectively). After 3 months, $53 \%$ of patients achieved a reduction in both $\mathrm{HbA1c}$ and $\mathrm{BW}$; the same holds true for $45 \%$ of patients at the 6-month mark. Similar results were observed both in general and diabetologist practices. In multivariate analyses, baseline $\mathrm{HbA} 1 \mathrm{c}$ (parameter estimate: -0.6479$)$ and diabetologist care $(-0.2553)$ were independent predictors of HbA1c change (6 months) (all $P<0.05)$.

Conclusion: T2D patients treated with dapagliflozin therapy achieved statistically significant reductions in $\mathrm{HbA1c}, \mathrm{BW}$, and SBP in a real-world primary and diabetologist care setting. The changes were comparable to the results of the dapagliflozin clinical trial program.

Keywords: type 2 diabetes, dapagliflozin, HbA1c, body mass index, systolic blood pressure

\section{Introduction}

Renal glucose production increases with insulin resistance, the hallmark of type 2 diabetes (T2D). ${ }^{1}$ Approximately $40 \%$ of the increased endogenous glucose release in patients with T2D has been attributed to renal gluconeogenesis. ${ }^{1}$ Furthermore, the capacity for renal glucose reabsorption is higher in patients with T2D, thus perpetuating hyperglycemia. ${ }^{2}$ SGLT2 is located in the proximal tubule and is involved in the reabsorption of glucose $(\sim 90 \%)$ in the kidney. ${ }^{3}$ As the action of SGLT2 is independent of insulin, its inhibition should not be influenced by the degree of insulin resistance or insulin secretion. ${ }^{4}$ Therefore, SGLT2 inhibitors have the potential to be effective in reducing hyperglycemia by stimulating urinary glucose excretion at any stage and duration of T2D. In 2015, the 
American Diabetes Association and European Association for the Study of Diabetes issued an update to their joint position statement on the management of hyperglycemia in T2D. ${ }^{5}$ SGLT2 inhibitors are mentioned among the options for secondline therapy after treatment with metformin and as alternative first-line options in patients with contraindications to metformin in an oral triple therapy or as add-on to insulin therapy. ${ }^{5}$

Dapagliflozin was the first approved selective SGLT2 inhibitor in Europe that reduces hyperglycemia through the reduction of glucose reabsorption into the kidney. ${ }^{6}$ Previous randomized clinical studies on dapagliflozin have demonstrated reductions in glycated hemoglobin (HbA1c) at all stages of T2D progression, favorable effects on body weight (BW), and a moderate lowering of blood pressure. These benefits have been observed when dapagliflozin was used as monotherapy or in combination with metformin (normal and extended release formulations), sulfonylureas, dipeptidyl peptidase-4 (DPP-4) inhibitors, or insulin. ${ }^{7-16}$ However, there is a paucity of data on the efficacy of dapagliflozin in a real-world setting, eg, in primary care patients with T2D. Furthermore, studies to determine baseline characteristics that could be used to predict which patients would benefit most from dapagliflozin treatment are lacking.

The first aim of this study was to investigate changes in treatment outcomes $(\mathrm{HbA} 1 \mathrm{c}, \mathrm{BW}$, systolic blood pressure [SBP]) for T2D patients initiating dapagliflozin therapy using a large database representative of practices in Germany. The second aim was to evaluate baseline clinical predictors of changes in $\mathrm{HbA} 1 \mathrm{c}$, weight, and SBP after dapagliflozin initiation.

\section{Methods}

The Disease Analyzer database (IMS Health GmbH \& Co. $\mathrm{OHG}$ ) collects drug prescriptions, diagnoses, and basic medical and demographic data directly obtained from the computer system of a representative sample of general practitioners and internal medicine practices throughout Germany. ${ }^{17}$ For such studies based on anonymous data in Germany no special ethic approval or patient consent is required and hence it was not sought for this study. The analyzed database period for the current study was from December 2012 to October 2014 (985 general and 32 diabetologist practices). Patients with T2D who were initiated on dapagliflozin therapy during the study period (index date) were included. Two cohorts with $\geq 3$ - or $\geq 6$-month follow-up after index date were analyzed, respectively. The practice visit records were used to determine baseline demographic characteristics 6 months prior to the index date.

Macrovascular complications were determined based on primary care diagnoses (ICD-10 codes) for coronary heart disease (I24, I25), myocardial infarction (I21, I22, I23, I25.2), stroke (I63, I64, G45), and peripheral vascular disease (I739, E105, E115, E145). Microvascular complications included retinopathy (E113, E143, H360), neuropathy (E114, E144), and nephropathy (N18, N19, E112, E142, Z49, Z992). Treatment with antidiabetic drugs prior to the index date was also assessed. Finally, the recorded $\mathrm{HbAlc}$ values and the documented BW and SBP before and after the index date were included in the analyses.

Descriptive statistics were provided and changes in HbA1c, BW, and blood pressure were assessed using paired $t$-tests. Two-sided tests were used and a $P$-value of $<0.05$ was considered as statistically significant. Scatter plots were used to visualize changes in BW and changes in HbA1c. Multivariate linear regression model was fitted to investigate the associations between clinical variables or comorbidity and changes in $\mathrm{HbAlc}$, BW, and SBP, respectively. All analyses were carried out in accordance with the Good Practice of Secondary Data Analysis (GPS): guidelines and recommendations of the German Society ${ }^{18}$ using SAS 9.3 (SAS Institute, Cary, NC, USA).

\section{Results}

Upon patient selection, 1,169 new users of dapagliflozin (age: 62.5 years; male: $59.3 \%$ ) were included. The baseline clinical characteristics are shown in Table 1 . Approximately $25 \%$ of the T2D patients who received dapagliflozin were treated by diabetologists. There was a high prevalence of privately insured patients. Approximately $10 \%$ of the patients received dapagliflozin monotherapy, whereas biguanides were the antidiabetic drug most frequently prescribed in combination with dapagliflozin, followed by insulin (Table 1).

Macrovascular complications and related risk factors were frequently found in the T2D patients initiating dapagliflozin therapy (Table 1). Coronary heart disease, peripheral vascular disease, history of myocardial infarction, or stroke was diagnosed in $47 \%$ of the patients prior to onset of dapagliflozin treatment. Microvascular diabetes complications were observed in $22 \%$ of the study population (Table 1).

At 3 months, a statistically significant reduction in mean HbA1c from baseline $(8.5 \%)$ was observed with dapagliflozin $(-0.8 \%)(P<0.001)$ (Table 2$)$. The reduction in $\mathrm{HbA} 1 \mathrm{c}$ with dapagliflozin treatment was maintained at 6 months $(-0.8 \%$ : standard deviation $[\mathrm{SD}]: 1.4)(P<0.001)$ (Table 3). Greater HbA1c decreases were observed with dapagliflozin in 466 patients with higher baseline $\mathrm{HbAlc}$ $>8.0 \%(-1.3 \%$; SD: 1.5$)(P<0.001)$ and 251 patients with 
$>9.0 \%(-1.8 \%$; SD: 1.7$)(P<0.001)$ at 3 months, and these greater reductions were still evident at 6 months (data not shown).

A statistically significant reduction in mean BW was observed in patients treated with dapagliflozin at 3 months $(-2.3 \mathrm{~kg})$ (Table 2) and was maintained through 6 months $(-2.5 \mathrm{~kg})$ (Table 3) (both $P<0.001)$. The mean reduction in SBP was statistically significant at 3 months $(-2.2 \mathrm{mmHg})$ and was also maintained at 6 months $(-2.3 \mathrm{~mm} \mathrm{Hg})$ (both

Table I Baseline characteristics of type 2 diabetes patients who received newly prescribed dapagliflozin in primary care practices in Germany (Disease Analyzer)

\begin{tabular}{ll}
\hline Variables & \\
\hline $\mathbf{N}$ & $\mathrm{I}, 169$ \\
Age (years) & 62.5 (II.2) \\
Male (\%) & 59.3 \\
Private health insurance coverage (\%) & 12.9 \\
Diabetologist care (\%) & 22.7 \\
Dapagliflozin therapy (\%) & \\
Monotherapy & 10.9 \\
Dapagliflozin + metformin & 37.1 \\
Dapagliflozin + insulin ( \pm metformin) & 33.5 \\
Dapagliflozin + DPP-4i ( \pm metformin) & 9.7 \\
Other combinations & 8.9 \\
Comorbidity (\%) & \\
Macrovascular complications & 47.1 \\
Microvascular complications & 22.8 \\
Hypertension & 78.8 \\
Hyperlipidemia & 62.0 \\
\hline Note Data
\end{tabular}

Notes: Data are mean (SD) or proportions (\%) DPP-4i. Macrovascular complications include coronary heart disease, myocardial infarction, peripheral vascular disease, and stroke. Microvascular complications include retinopathy, nephropathy, and neuropathy.

Abbreviations: DPP-4i, dipeptidyl peptidase-4 inhibitor; SD, standard deviation.
$P<0.05$ ) (Tables 2 and 3). The effects of dapagliflozin on $\mathrm{HbA} 1 \mathrm{c}$ and BW were largely comparable in both T2D patients treated in general practices and diabetologist care (Tables 2 and 3). The reductions in SBP at both 3 and 6 months were somewhat greater in patients treated by diabetologists compared to patients in general practices.

Scatter plots representing the relationship between reductions in $\mathrm{HbA} 1 \mathrm{c}$ and $\mathrm{BW}$ after 3 and 6 months of treatment are shown in Figures 1 and 2, respectively. Approximately $50 \%$ of patients receiving dapagliflozin responded simultaneously to the two-item endpoint of combined $\mathrm{HbAlc}(>0 \% \mathrm{HbA} 1 \mathrm{c} \%)$ and $\mathrm{BW}(>0 \mathrm{~kg})$ reductions at 3 months (Figure 1). The combined endpoint reductions were achieved in $45 \%$ of new dapagliflozin patients after 6 months (Figure 2). Furthermore, $\sim 19 \%$ of patients treated with dapagliflozin achieved an $\mathrm{HbA} 1 \mathrm{c}$ reduction at 3 months despite an increase in BW (Figure 1). At 6 months, this proportion increased to $25 \%$ (Figure 2). After 3 months of dapagliflozin treatment, only $8.5 \%$ failed to exhibit reductions in both $\mathrm{HbA} 1 \mathrm{c}$ and BW. After 6 months, the corresponding proportion was $12.4 \%$.

The correlations of baseline clinical variables with changes in $\mathrm{HbAl} \mathrm{c}$ after onset of dapagliflozin treatment were investigated using linear regression. Only baseline $\mathrm{HbA1c}$ was statistically significantly inversely related to change in HbA1c after both 3 and 6 months, indicating that higher $\mathrm{HbA1c}$ values were related to a greater decrease after onset of dapagliflozin treatment $(P<0.0001)$. Furthermore, age was positively correlated with the HbAlc decrease observed at 3 months, indicating that $\mathrm{HbAlc}$ increased with age after the index date (Table 4). Finally, diabetologist treatment

Table 2 Three-month (after the ID) changes in HbAlc, body weight, and systolic blood pressure in type 2 diabetes patients initiating dapagliflozin therapy in primary care practices in Germany

\begin{tabular}{|c|c|c|c|c|c|}
\hline Variables & $\mathbf{N}$ & $\begin{array}{l}\text { Baseline } \leq 6 \text { months } \\
\text { before ID }\end{array}$ & 3 months after ID & $\begin{array}{l}\text { Difference } \\
\text { (before-after ID) }\end{array}$ & $P$-value \\
\hline \multicolumn{6}{|l|}{ Total patients } \\
\hline HbAlc (\%) & 826 & $8.5(1.5)$ & $7.8(1.2)$ & $-0.8(1.4)$ & $<0.001$ \\
\hline Body weight (kg) & 268 & $102.7(22.1)$ & $100.4(21.6)$ & $-2.3(4.8)$ & $<0.001$ \\
\hline Systolic blood pressure (mmHg) & 471 & $137.0(\mid 4.5)$ & I34.8 (I7.3) & $-2.2(17.6)$ & 0.003 \\
\hline \multicolumn{6}{|c|}{ Patients treated by general practitioners } \\
\hline $\mathrm{HbAlc}(\%)$ & 682 & $8.6(1.5)$ & $7.8(1.2)$ & $-0.8(1.4)$ & $<0.001$ \\
\hline Body weight (kg) & 180 & $99.7(22.2)$ & $97.4(21.4)$ & $-2.3(4.9)$ & $<0.001$ \\
\hline Systolic blood pressure $(\mathrm{mmHg})$ & 326 & $136.9(17.4)$ & I35.I (I7.2) & $-1.8(17.2)$ & 0.046 \\
\hline \multicolumn{6}{|l|}{ Patients treated by diabetologists } \\
\hline $\mathrm{HbAlc}(\%)$ & 144 & $8.4(1.3)$ & $7.8(1.2)$ & $-0.6(1.3)$ & $<0.001$ \\
\hline Body weight $(\mathrm{kg})$ & 88 & $108.9(20.9)$ & $106.4(20.9)$ & $-2.5(4.8)$ & $<0.001$ \\
\hline Systolic blood pressure $(\mathrm{mmHg})$ & 145 & I37.2(17.7) & $134.2(17.6)$ & $-3.0(18.6)$ & 0.016 \\
\hline
\end{tabular}

Note: Data are mean (SD).

Abbreviations: ID, index date; SD, standard deviation; HbAlc, glycated hemoglobin. 
Table 3 Six-month (after the ID) changes in $\mathrm{HbAlc}$, body weight, and systolic blood pressure in type 2 diabetes patients initiating dapagliflozin therapy in primary care practices in Germany

\begin{tabular}{|c|c|c|c|c|c|}
\hline Variables & $\mathbf{N}$ & $\begin{array}{l}\text { Baseline } \leq 6 \text { months } \\
\text { before ID }\end{array}$ & 6 months after ID & $\begin{array}{l}\text { Difference } \\
\text { (before-after ID) }\end{array}$ & $P$-value \\
\hline \multicolumn{6}{|l|}{ Total patients } \\
\hline $\mathrm{HbAlc}(\%)$ & 645 & $8.5(1.6)$ & $7.8(1.2)$ & $-0.8(1.5)$ & $<0.001$ \\
\hline Body weight (kg) & 239 & $102.3(22.5)$ & $99.8(22.1)$ & $-2.5(7.1)$ & $<0.001$ \\
\hline Systolic blood pressure $(\mathrm{mmHg})$ & 388 & $137.7(16.7)$ & I35.4 (I6.2) & $-2.3(16.7)$ & 0.011 \\
\hline \multicolumn{6}{|l|}{$\begin{array}{l}\text { Patients treated by general } \\
\text { practitioners }\end{array}$} \\
\hline $\mathrm{HbAlc}(\%)$ & 530 & $8.5(1.6)$ & $7.8(1.2)$ & $-0.7(1.5)$ & $<0.001$ \\
\hline Body weight (kg) & 167 & $98.9(21.7)$ & $96.4(21.3)$ & $-2.5(5.4)$ & $<0.001$ \\
\hline Systolic blood pressure (mmHg) & 265 & $137.6(16.9)$ & I35.7 (I6.5) & $-2.0(15.9)$ & 0.064 \\
\hline \multicolumn{6}{|l|}{ Patients treated by diabetologists } \\
\hline $\mathrm{HbAlc}(\%)$ & 115 & $8.6(1.5)$ & $7.7(1.2)$ & $-0.9(1.3)$ & $<0.001$ \\
\hline Body weight (kg) & 72 & II $0.1(22.6)$ & $107.7(22.2)$ & $-2.5(9.9)$ & 0.031 \\
\hline Systolic blood pressure $(\mathrm{mmHg})$ & 123 & I37.8 (I6.4) & I34.8(I5.5) & $-2.9(18.3)$ & 0.073 \\
\hline
\end{tabular}

Note: Data are mean (SD).

Abbreviations: ID, index date; SD, standard deviation; HbAlc, glycated hemoglobin.

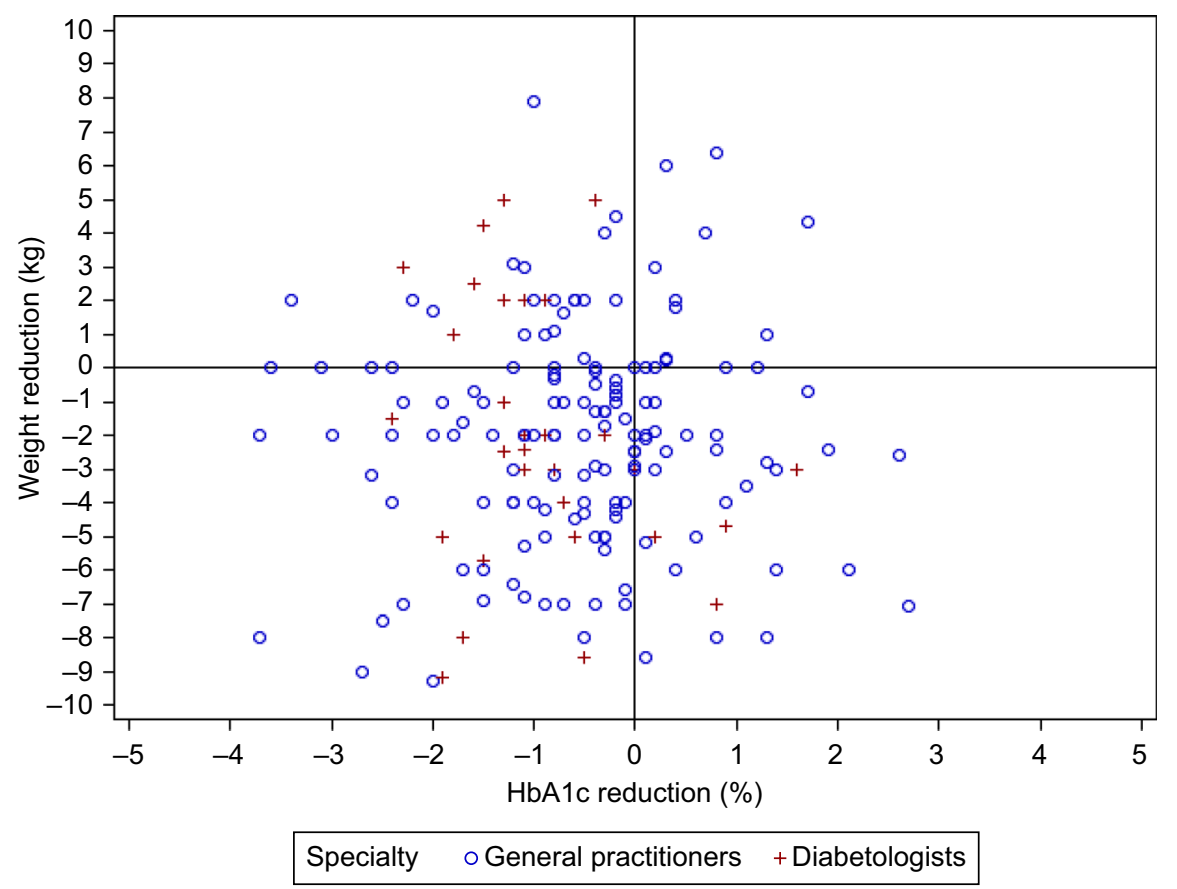

Figure I Scatter plot representing the relationship between the change in $\mathrm{HbAlc}(\%)$ and body weight (kg) after 3 months in type 2 diabetes patients initiating dapagliflozin treatment in primary care practices.

Abbreviation: HbAlc, glycated hemoglobin.

was related to a significantly greater decrease in $\mathrm{HbA} 1 \mathrm{c}$ at 6 months compared to treatment in general practices.

Baseline BW was inversely related to weight change $(\mathrm{kg})$ both at 3 and 6 months, indicating that higher BW was related to a greater change after onset of dapagliflozin treatment (Table 5). Furthermore, diabetologist care was related to a greater weight change at 3 months after onset of dapagliflozin therapy compared to treatment in general practices.

With respect to changes in SBP at 3 months, only baseline systolic values (negative) and age (positive) were statistically significantly related (data not shown). Thus, higher baseline SBP was related to a greater decrease. At 6 months, only baseline SBP was negatively related to its change; this change was statistically significant.

Changes in $\mathrm{HbA1c}, \mathrm{BW}$, and SBP in various subgroups of patients treated with antidiabetic combination therapies, including dapagliflozin, are shown in Tables S1 and S2. After 3 months of treatment, both dapagliflozin monotherapy and combination therapy with metformin, insulin, or DPP-4 inhibitors yielded statistically significant decreases of $\mathrm{HbA} 1 \mathrm{c}$ 


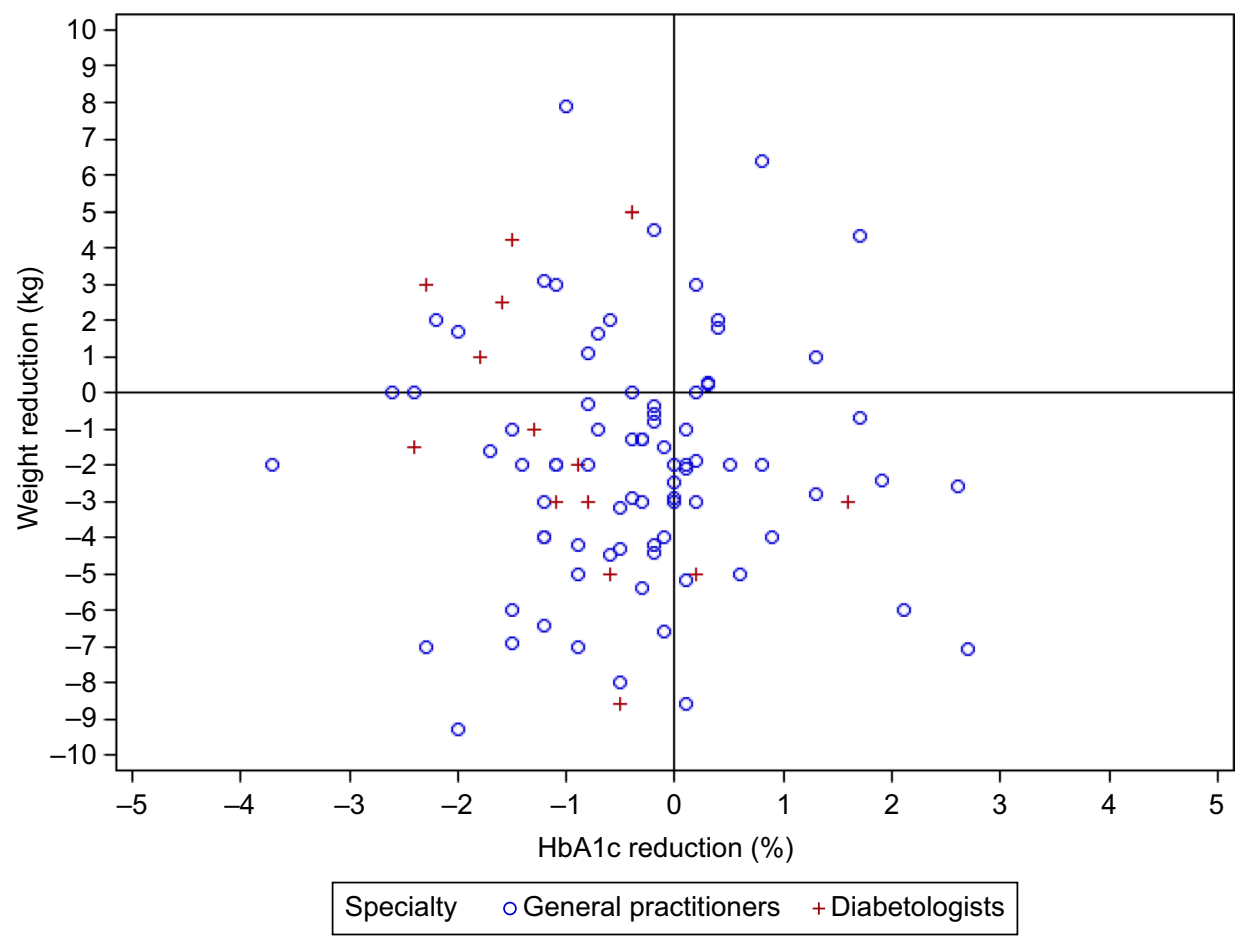

Figure 2 Scatter plot representing the relationship between the change in HbAlc (\%) and weight (kg) after 6 months in type 2 diabetes patients initiating dapagliflozin treatment in primary care practices.

Abbreviation: $\mathrm{HbAlc}$, glycated hemoglobin.

Table 4 Variables associated with HbAlc (\%) change after 3 and 6 months in type 2 diabetes patients initiating dapagliflozin in primary care practices: multivariate linear regression models

\begin{tabular}{|c|c|c|c|c|}
\hline Variables & $\begin{array}{l}\text { Change ( } 3 \text { months) } \\
\text { beta-coefficients }\end{array}$ & $P$-value & $\begin{array}{l}\text { Change ( } 6 \text { months) } \\
\text { beta-coefficients }\end{array}$ & $P$-value \\
\hline Age (per year) & 0.0073 & $0.038 I$ & 0.0055 & 0.1995 \\
\hline HbA Ic (baseline) (\%) & -0.6124 & $<0.0001$ & -0.6479 & $<0.0001$ \\
\hline Male gender & -0.0493 & 0.5169 & -0.1023 & 0.2619 \\
\hline Private health insurance coverage & -0.1487 & 0.1983 & 0.0605 & 0.6600 \\
\hline Diabetologist care & -0.0024 & 0.9817 & -0.2553 & 0.0391 \\
\hline Dapagliflozin monotherapy & 0.1096 & 0.5269 & 0.0834 & 0.6701 \\
\hline Dapagliflozin + insulin ( \pm metformin) & 0.0773 & 0.5774 & 0.1021 & 0.5104 \\
\hline Dapagliflozin + DPP-4i ( \pm metformin) & -0.1287 & 0.3450 & -0.1260 & 0.4143 \\
\hline Other combinations & 0.0237 & 0.8892 & -0.0227 & 0.9060 \\
\hline Macrovascular complications & -0.0180 & 0.8135 & -1.6027 & 0.0929 \\
\hline Microvascular complications & -0.0990 & 0.2845 & -0.0912 & 0.3844 \\
\hline Hypertension & -0.1217 & 0.1964 & 0.0935 & 0.4158 \\
\hline Hyperlipidemia & -0.0247 & 0.7512 & 0.0513 & 0.5879 \\
\hline
\end{tabular}

Note: Bold text indicate that the effect is significant.

Abbreviations: DPP-4i, dipeptidyl peptidase-4 inhibitor; HbAlc, glycated hemoglobin.

and BW (Table S1). A statistically significant reduction of SBP was also observed in patients treated with dapagliflozin and DPP-4 inhibitors. After 6 months of treatment, similar statistically significant reductions of $\mathrm{HbAlc}$ and $\mathrm{BW}$ were found for dapagliflozin monotherapy (Table S2). Moreover, a statistically significant decrease in $\mathrm{HbA1c}$ and BW was observed for dapagliflozin combination therapy with insulin or DPP-4 inhibitors. A statistically significant HbA1c reduction was maintained in patients with dual treatment with metformin, whereas a borderline statistical significance was found for BW $(P=0.06)$. With respect to SBP, no statistically significant decrease was observed in all four treatment subgroups after 6 months of treatment. However, patient numbers are small in several of these groups, thus limiting statistical power.

\section{Discussion}

For the first time, a real-world study evaluated the shortterm changes in $\mathrm{HbA} 1 \mathrm{c}, \mathrm{BW}$, and SBP in T2D patients initiating dapagliflozin treatment in primary care and 
Table 5 Variables associated with body weight change $(\mathrm{kg})$ after 3 and 6 months in type 2 diabetes patients initiating dapagliflozin in primary care practices: multivariate linear regression model

\begin{tabular}{|c|c|c|c|c|}
\hline Variables & $\begin{array}{l}\text { Change ( } 3 \text { months) } \\
\text { parameter estimate }\end{array}$ & $P$-value & $\begin{array}{l}\text { Change ( } 6 \text { months) } \\
\text { beta-coefficients }\end{array}$ & P-values \\
\hline Age (per year) & 0.0055 & 0.1995 & -0.0147 & 0.7682 \\
\hline Body weight baseline (per kg) & -0.6479 & $<0.0001$ & -0.0847 & 0.0003 \\
\hline Male gender & -0.1023 & 0.2619 & 0.6923 & 0.4843 \\
\hline Private health insurance coverage & 0.0605 & 0.6600 & -1.4899 & 0.3785 \\
\hline Diabetologist care & -0.2553 & 0.0391 & -0.3018 & 0.7790 \\
\hline Dapagliflozin monotherapy & 0.0834 & 0.6701 & -2.9286 & 0.1779 \\
\hline Dapagliflozin + insulin ( \pm metformin) & 0.1021 & 0.5104 & 1.0618 & 0.5308 \\
\hline Dapagliflozin + DPP-4i ( \pm metformin) & -0.1259 & 0.4143 & -0.7029 & 0.6894 \\
\hline Other combinations & -0.0227 & 0.9060 & -0.1178 & 0.9575 \\
\hline Macrovascular complications & 0.3595 & 0.5658 & -1.6027 & 0.0929 \\
\hline Microvascular complications & $0.397 \mid$ & 0.5529 & 0.9438 & 0.3827 \\
\hline Hypertension & 0.1935 & 0.4158 & 1.3511 & 0.2697 \\
\hline Hyperlipidemia & 0.0513 & 0.5879 & -1.6202 & 0.0999 \\
\hline
\end{tabular}

Note: Bold text indicate that the effect is significant.

Abbreviation: DPP-4i, dipeptidyl peptidase-4 inhibitor.

diabetologist practices. Overall, T2D patients treated with dapagliflozin exhibited statistically significant reductions in $\mathrm{HbA} 1 \mathrm{c}(-0.8 \%)$, BW $(-2.5 \mathrm{~kg})$, and SBP $(-2.3 \mathrm{mmHg})$ after 6 months of treatment. In addition, $\mathrm{HbAlc}$ reductions were greater in patients with poor glycemic control. These real-world treatment effects are comparable to results of dapagliflozin randomized clinical trials. ${ }^{7-15,18-21,26}$

\section{Changes in $\mathrm{HbAlc}$}

In the dapagliflozin clinical trial program, monotherapy yielded a statistically significant $\mathrm{HbA} 1 \mathrm{c}$ reduction of $0.66 \%$ after 24 weeks when compared to placebo $(-0.89 \%$ vs $-0.23 \%, P<0.0001) .^{7}$ As an add-on to metformin, dapagliflozin consistently improved $\mathrm{HbA} 1 \mathrm{c}$ (placebo-corrected) by $0.54 \%$ after 24 weeks $(-0.84 \%$ vs $-0.30 \%, P<0.0001) .{ }^{8}$ In third-line therapy, when dapagliflozin was used concomitant with the DPP-4 inhibitors sitagliptin or saxagliptin, HbA1c reductions of $-0.5 \%(-0.5 \%$ vs $0.0 \%, P<0.0001)$ and $-0.72 \%$ $(-0.82 \%$ vs $0.10 \%, P<0.0001)$, respectively, were observed compared with placebo after 24 weeks. ${ }^{10,16}$ In third-line therapy with metformin and sulfonylureas, dapagliflozin led to placebo-corrected $\mathrm{HbA} 1 \mathrm{c}$ reductions of $-0.69 \%$ $(P<0.0001) .{ }^{15}$ Moreover, addition of dapagliflozin in T2D patients receiving high doses of insulin ( $\geq 30 \mathrm{IU} /$ day) and up to two other antidiabetic agents effectively reduced $\mathrm{HbAlc}$ by $0.57 \%$ compared with placebo after 24 weeks $(-0.96$ vs $-0.39 \%, P<0.001)^{11}$ and by $0.35 \%$ over a period of 2 years $(-0.78 \%$ vs $-0.43 \%, P<0.0007)$ with stable insulin doses over the entire study period and a net increase of placebo by 19.2 IU at 2 years when compared to the study drug. ${ }^{19}$

In the present study, the $\mathrm{HbA} 1 \mathrm{c}$ reduction of $0.8 \%$ achieved with dapagliflozin after 3 and 6 months was commensurate with most $\mathrm{HbA} 1 \mathrm{c}$ reductions over 24 weeks found in the dapagliflozin arm of clinical trials, rather than their placebo-corrected margin.

Similar results were obtained for the second largest cohort of patients using dapagliflozin as an add-on to insulin (33\%). This cohort exhibited an $\mathrm{HbA1c}$ reduction of $0.8 \%$ after 6 months. Identical numerical reduction of $\mathrm{HbAlc}$ at 6 months was shown for the oral triple therapy adding dapagliflozin to a preexisting treatment with metformin and a DPP-4 inhibitor. This observation in real-life yielded reductions similar to the recently published clinical trial using dapagliflozin as a thirdline drug add-on to metformin and saxagliptin. ${ }^{16}$

This analysis also indicated clinical variables that are independently related to change in $\mathrm{HbA} 1 \mathrm{c}$ after initiation of dapagliflozin treatment. Most important, the baseline HbAlc was inversely related to both the changes in $\mathrm{HbA1c}$ at 3 and 6 months. This result is in accordance with a recent clinical trial with statistically significantly greater $\mathrm{HbA} 1 \mathrm{c}$ reductions observed with dapagliflozin treatment in patients with baseline $\mathrm{HbA} 1 \mathrm{c} \geq 8.0 \%(-0.56 \%)$ and $\geq 9.0 \%(-0.99 \%)$ at 6 months compared to the overall sample $(-0.46 \%) .^{20}$

In this real-world study, a greater $\mathrm{HbA1c}$ reduction was found in patients treated in diabetologist practices. This outcome most likely reflects the fact that diabetologists are more familiar with the relatively new dapagliflozin therapy. The positive correlation with age found in the present study ostensibly indicates that older patients have a more advanced stage of the disease along with declining kidney function, which makes it more difficult to achieve a reduction in $\mathrm{HbA} 1 \mathrm{c}$ using dapagliflozin.

Taken together, dapagliflozin usage in real life favorably reflected the $\mathrm{HbA1c}$ reductions previously measured in the 
dapagliflozin clinical trial program. Higher baseline HbA1c values led to greater reductions and if higher age is associated with decreasing kidney function, smaller reductions are well explainable due to dapagliflozin's mechanism of action.

\section{Changes in body weight}

The weight loss observed in the present study was consistent with the weight loss observed across RCTs in clinical trials. ${ }^{21}$ Twelve RCTs, including 2,005 participants in the intervention groups and 2,003 participants in the control groups with follow-up durations ranging from 12 to 104 weeks, were included in a meta-analysis. ${ }^{21} \mathrm{BW}$ decreases ranged from -3.33 to $-1.54 \mathrm{~kg}$ after treatment with dapagliflozin. ${ }^{21}$ The overall mean difference between the intervention and control groups was $-2.10 \mathrm{~kg}(P<0.001){ }^{21}$ In another network metaanalysis of RCTs, the mean change in weight associated with dapagliflozin was statistically significant compared with the other antidiabetic agents: $-2.74 \mathrm{~kg}$ relative to DPP-4 inhibitors, and $-4.67 \mathrm{~kg}$ relative to sulfonylureas. ${ }^{22}$ The results from the present real-world study demonstrate that similar reductions in $\mathrm{BW}(-2.5 \mathrm{~kg}$ at 6 months) can be achieved in primary care patients. This weight loss has been attributed to the $\sim 200-300$ cal of glucose excreted per day as a result of treatment with dapagliflozin. ${ }^{23}$ Although the impact of this amount of weight loss on mortality and cardiovascular events is debatable, even small weight decreases in T2D have been shown to improve treatment satisfaction and quality of life. ${ }^{24,25}$

Similar to $\mathrm{HbA1c}$, baseline BW was negatively correlated with weight change at 3 months. The BW reduction observed in clinical trials for dapagliflozin was primarily caused by a reduction in body fat mass, as shown by dual energy X-ray absorptiometry and calorie loss. ${ }^{26} \mathrm{~A}$ subgroup analysis using magnetic resonance imaging showed a reduction of visceral adipose tissue mass greater than $9 \%$ compared to the baseline during treatment with dapagliflozin. Furthermore, consistent with the changes in $\mathrm{HbA1c}$, diabetologist care was associated with a greater change in BW at 3 months. This most likely reflects more intensive care and/or a more motivated patient population.

\section{Changes in systolic blood pressure}

A recent meta-analysis of 27 RCTs involving dapagliflozin $(n=12)$ reported that SGLT2 inhibitor use was associated with a statistically significant reduction in SBP from baseline $(-4.0 \mathrm{mmHg}) .{ }^{27}$ This real-world study also showed statistically significant reductions in SBP $(-2.3 \mathrm{mmHg})$ at 6 months. The impact of the blood pressure reductions achieved with dapagliflozin on cardiovascular outcomes requires further investigation. The underlying mechanisms of a dapagliflozin-specific reduction of SBP must be identified. In the present investigation, baseline blood pressure (inverse association) was the only relevant variable associated with changes in SBP.

\section{Strength and limitations of the study}

The present study provides an illustration of prescriptions and diagnoses in primary care and diabetologist practices in Germany. The strength of the study is the use of a large nationwide database and the unbiased assessment of prescriptions and outcomes. As this study used primary care records, a number of limitations should be mentioned: First, no valid information regarding onset of diabetes was provided. Additionally, assessment of comorbidities solely relied on ICD codes filled in by physicians. Moreover, measurements of HbA1c and body mass index values were not standardized. Finally, data on socioeconomic status and lifestyle-related risk factors were also unavailable. It must also be mentioned that, in this study, the adherence to the dapagliflozin administration was not assessed. No investigation was also performed about the change of other antihyperglycemic drugs during the study period. Both adherence and therapy change might affect the findings.

\section{Conclusion}

This is the first report of real-world outcomes concerning the effect of dapagliflozin on $\mathrm{HbA1c}, \mathrm{BW}$, and systolic blood pressure in $\mathrm{T} 2 \mathrm{D}$ patients in primary care and diabetologist practices. The absolute reductions in $\mathrm{HbA} 1 \mathrm{c}(-0.8 \%)$, BW $(-2.5 \mathrm{~kg})$, and SBP $(-2.3 \mathrm{mmHg})$ observed in patients inadequately controlled with other antidiabetic agents and insulin were similar to results from the dapagliflozin clinical trial program.

\section{Acknowledgment}

The study was supported by AstraZeneca GmbH, Germany.

\section{Disclosure}

MF Scheerer, R Rist, and O Proske are employees of AstraZeneca GmbH, Germany. Karel Kostev and Annika Meng are employees of IMS Health GmbH \& Co. OHG. The authors report no other conflicts of interest in this work.

\section{References}

1. Gerich JE. Role of the kidney in normal glucose homeostasis and in the hyperglycaemia of diabetes mellitus: therapeutic implications. Diabet Med. 2010;27(2):136-142.

2. Rahmoune H, Thompson PW, Ward JM, Smith CD, Hong G, Brown J. Glucose transporters in human renal proximal tubular cells isolated from the urine of patients with non-insulin-dependent diabetes. Diabetes. 2005;54(12):3427-3434.

3. Wright EM, Loo DD, Hirayama BA. Biology of human sodium glucose transporters. Physiol Rev. 2011;91(2):733-794. 
4. Brunton SA. The potential role of sodium glucose co-transporter 2 inhibitors in the early treatment of type 2 diabetes mellitus. Int J Clin Pract. 2015;69(10):1071-1087.

5. Inzucchi SE, Bergenstal RM, Buse JB, et al. Management of hyperglycaemia in type 2 diabetes, 2015: a patient-centred approach. Update to a position statement of the American Diabetes Association and the European Association for the Study of Diabetes. Diabetologia. 2015;58(3):429-442.

6. Hinnen D. Glucuretic effects and renal safety of dapagliflozin in patients with type 2 diabetes. Ther Adv Endocrinol Metab. 2015;6(3):92-102.

7. Ferrannini E, Ramos SJ, Salsali A, Tang W, List JF. Dapagliflozin monotherapy in type 2 diabetic patients with inadequate glycemic control by diet and exercise: a randomized, double-blind, placebo-controlled, phase 3 trial. Diabetes Care. 2010;33(10):2217-2224.

8. Bailey CJ, Gross JL, Pieters A, Bastien A, List JF. Effect of dapagliflozin in patients with type 2 diabetes who have inadequate glycaemic control with metformin: a randomised, double-blind, placebo-controlled trial. Lancet. 2010;375(9733):2223-2233.

9. Strojek K, Yoon KH, Hruba V, Elze M, Langkilde AM, Parikh S. Effect of dapagliflozin in patients with type 2 diabetes who have inadequate glycaemic control with glimepiride: a randomized, 24-week, double-blind, placebo-controlled trial. Diabetes Obes Metab. 2011;13(10):928-938.

10. Jabbour SA, Hardy E, Sugg J, Parikh S; Study 10 Group. Dapagliflozin is effective as add-on therapy to sitagliptin with or without metformin: a 24-week, multicenter, randomized, double-blind, placebo-controlled study. Diabetes Care. 2014;37(3):740-750.

11. Wilding JP, Woo V, Soler NG, Pahor A, Sugg J, Rohwedder K, Parikh $\mathrm{S}$; Dapagliflozin 006 Study Group. Long-term efficacy of dapagliflozin in patients with type 2 diabetes mellitus receiving high doses of insulin: a randomized trial. Ann Intern Med. 2012;156(6):405-415.

12. Nauck MA, Del Prato S, Meier JJ, Durán-García S, Rohwedder K, Elze M, Parikh SJ. Dapagliflozin versus glipizide as add-on therapy in patients with type 2 diabetes who have inadequate glycemic control with metformin: a randomized, 52-week, double-blind, active-controlled noninferiority trial. Diabetes Care. 2011;34(9):2015-2022.

13. Henry RR, Murray AV, Marmolejo MH, Hennicken D, Ptaszynska A, List JF. Dapagliflozin, metformin XR, or both: initial pharmacotherapy for type 2 diabetes, a randomised controlled trial. Int J Clin Pract. 2012;66(5):446-456.

14. Matthaei S, Catrinoiu D, Celiński A, et al. A randomized, doubleblind trial of triple therapy with saxagliptin add-on to dapagliflozin plus metformin in patients with type 2 diabetes. Diabetes Care. 2015;38(11):2018-2024.

15. Matthaei S, Bowering K, Rohwedder K, Grohl A, Parikh S; Study 05 Group. Dapagliflozin improves glycemic control and reduces body weight as add-on therapy to metformin plus sulfonylurea: a 24-week randomized, double-blind clinical trial. Diabetes Care. 2015;38(3):365-372.
16. Becher H, Kostev K, Schröder-Bernhardi D. Validity and representativeness of the "Disease Analyzer" patient database for use in pharmacoepidemiological and pharmacoeconomic studies. Int J Clin Pharmacol Ther. 2009;47(10):617-626.

17. Swart E, Gothe H, Geyer S, Jaunzeme J, Maier B, Grobe TG, Ihle P. [Good Practice of Secondary Data Analysis (GPS): guidelines and recommendations]. Gesundheitswesen. 2015;77(2):120-126. German.

18. Mathieu C, Ranetti AE, Li D, et al. Randomized, double-blind, phase 3 trial of triple therapy with dapagliflozin add-on to saxagliptin plus metformin in type 2 diabetes. Diabetes Care. 2015;38(11):2009-2017.

19. Wilding JP, Woo V, Rohwedder K, Sugg J, Parikh S; Dapagliflozin 006 Study Group. Dapagliflozin in patients with type 2 diabetes receiving high doses of insulin: efficacy and safety over 2 years. Diabetes Obes Metab. 2014;16(2):124-136.

20. Cefalu WT, Leiter LA, de Bruin TW, Gause-Nilsson I, Sugg J, Parikh SJ. Dapagliflozin's effects on glycemia and cardiovascular risk factors in high-risk patients with type 2 diabetes: a 24-week, multicenter, randomized, double-blind, placebo-controlled study with a 28 -week extension. Diabetes Care. 2015;38(7):1218-1227.

21. Sun YN, Zhou Y, Chen X, Che WS, Leung SW. The efficacy of dapagliflozin combined with hypoglycaemic drugs in treating type 2 diabetes mellitus: meta-analysis of randomised controlled trials. BMJ Open. 2014;4(4):e004619.

22. Goring S, Hawkins N, Wygant G, Roudaut M, Townsend R, Wood I, Barnett AH. Dapagliflozin compared with other oral anti-diabetes treatments when added to metformin monotherapy: a systematic review and network meta-analysis. Diabetes Obes Metab. 2014;16(5):433-442.

23. Whaley JM, Tirmenstein M, Reilly TP, Poucher SM, Saye J, Parikh S, List JF. Targeting the kidney and glucose excretion with dapagliflozin: preclinical and clinical evidence for SGLT2 inhibition as a new option for treatment of type 2 diabetes mellitus. Diabetes Metab Syndr Obes. 2012;5:135-148.

24. Grandy S, Fox KM, Bazata DD. Association of self-reported weight change and quality of life, and exercise and weight management behaviors among adults with type 2 diabetes mellitus: the SHIELD study. Cardiol Res Pract. 2012;2012:892564.

25. Pi-Sunyer FX. The impact of weight gain on motivation, compliance, and metabolic control in patients with type 2 diabetes mellitus. Postgrad Med. 2009;121(15):94-107.

26. Bolinder J, Ljunggren Ö, Johansson L, et al. Dapagliflozin maintains glycaemic control while reducing weight and body fat mass over 2 years in patients with type 2 diabetes mellitus inadequately controlled on metformin. Diabetes Obes Metab. 2014;16(2):159-169.

27. Baker WL, Smyth LR, Riche DM, Bourret EM, Chamberlin KW, White WB. Effects of sodium-glucose co-transporter 2 inhibitors on blood pressure: a systematic review and meta-analysis. J Am Soc Hypertens. 2014;8(4):262-275. 


\section{Supplementary materials}

Table SI Three-month changes (after the ID) in $\mathrm{HbAlc}$, body weight, and systolic blood pressure in type 2 diabetes patients initiating dapagliflozin therapy in primary care practices in Germany

\begin{tabular}{|c|c|c|c|c|c|}
\hline Variables & $\mathbf{N}$ & $\begin{array}{l}\text { Baseline } \leq 6 \text { months } \\
\text { before ID }\end{array}$ & 3 months after ID & Difference & $P$-value \\
\hline \multicolumn{6}{|l|}{ Dapagliflozin monotherapy } \\
\hline $\mathrm{HbAlc}(\%)$ & 72 & 8.1 (I.7) & $7.7(1.4)$ & $-0.4(1.2)$ & 0.010 \\
\hline Body weight (kg) & 24 & $110.0(27.6)$ & $105.3(25.7)$ & $-4.7(7.5)$ & $<0.001$ \\
\hline Systolic blood pressure $(\mathrm{mmHg})$ & 45 & I37.I (15.3) & $136.0(18.6)$ & $-1.1(17.6)$ & 0.499 \\
\hline \multicolumn{6}{|l|}{ Dapagliflozin + metformin } \\
\hline $\mathrm{HbAlc}(\%)$ & 73 & $8.3(1.6)$ & $7.7(1.2)$ & $-0.6(1.5)$ & $<0.001$ \\
\hline Body weight (kg) & 17 & $99.9(21.4)$ & $96.7(22.3)$ & $-3.2(3.7)$ & 0.002 \\
\hline Systolic blood pressure $(\mathrm{mmHg})$ & 37 & $135.4(18.1)$ & I34.5 (I4.8) & $-0.9(20.3)$ & 0.964 \\
\hline \multicolumn{6}{|l|}{ Dapagliflozin + insulin } \\
\hline $\mathrm{HbAlc}(\%)$ & 305 & $8.7(1.5)$ & $8.0(1.2)$ & $-0.8(1.4)$ & $<0.001$ \\
\hline Body weight $(\mathrm{kg})$ & 133 & $105.7(22.8)$ & $103.8(22.5)$ & $-1.9(5.0)$ & $<0.001$ \\
\hline Systolic blood pressure $(\mathrm{mmHg})$ & 223 & $137.0(17.8)$ & $135.4(18.1)$ & $-1.6(18.1)$ & 0.070 \\
\hline \multicolumn{6}{|l|}{ Dapagliflozin + DPP-4 inhibitors } \\
\hline HbAlc (\%) & 298 & $8.5(1.5)$ & $7.6(1.1)$ & $-0.9(1.4)$ & $<0.001$ \\
\hline Body weight $(\mathrm{kg})$ & 68 & $96.9(18.1)$ & $94.7(17.0)$ & $-2.1(3.6)$ & $<0.001$ \\
\hline Systolic blood pressure $(\mathrm{mmHg})$ & 128 & $139.0(18.1)$ & $135.4(17.2)$ & $-3.6(17.0)$ & 0.018 \\
\hline
\end{tabular}

Note: Data are presented as mean (SD). Bold text indicate that the effect is significant.

Abbreviations: DPP-4, dipeptidyl peptidase-4; ID, index date; SD, standard deviation; HbAlc, glycated hemoglobin.

Table S2 Six-month changes (after the ID) in HbAlc, body weight (kg), and systolic blood pressure in type 2 diabetes patients initiating dapagliflozin therapy in primary care practices in Germany

\begin{tabular}{|c|c|c|c|c|c|}
\hline Variables & $\mathbf{N}$ & $\begin{array}{l}\text { Baseline } \leq 6 \text { months } \\
\text { before ID }\end{array}$ & 6 months after ID & Difference & $P$-value \\
\hline \multicolumn{6}{|l|}{ Dapagliflozin monotherapy } \\
\hline $\mathrm{HbAlc}(\%)$ & 62 & $8.3(1.7)$ & $7.8(1.5)$ & $-0.6(1.3)$ & 0.001 \\
\hline Body weight (kg) & 20 & $108.3(30.8)$ & $102.2(29.2)$ & $-6.1(16.3)$ & 0.042 \\
\hline Systolic blood pressure $(\mathrm{mmHg})$ & 40 & I37.I (I5.3) & $136.0(\mid 8.6)$ & $-1.1(17.6)$ & 0.518 \\
\hline \multicolumn{6}{|l|}{ Dapagliflozin + metformin } \\
\hline $\mathrm{HbAlc}(\%)$ & 69 & $8.3(1.6)$ & $7.7(1.4)$ & $-0.6(1.6)$ & 0.001 \\
\hline Body weight (kg) & 21 & $102.7(20.9)$ & $100.6(21.2)$ & $-2.1(4.3)$ & 0.058 \\
\hline Systolic blood pressure $(\mathrm{mmHg})$ & 31 & $139.7(15.2)$ & I35.4 (I2.6) & $-4.4(17.2)$ & 0.129 \\
\hline \multicolumn{6}{|l|}{ Dapagliflozin + insulin } \\
\hline $\mathrm{HbAlc}(\%)$ & 233 & $8.7(1.6)$ & $7.9(1.2)$ & $-0.8(1.6)$ & $<0.001$ \\
\hline Body weight (kg) & 118 & $104.6(22.5)$ & $102.8(22.3)$ & $-1.9(6.4)$ & 0.007 \\
\hline Systolic blood pressure $(\mathrm{mmHg})$ & 180 & $137.2(16.7)$ & $135.0(17.3)$ & $-2.2(17.0)$ & 0.508 \\
\hline \multicolumn{6}{|c|}{ Dapagliflozin + DPP-4 inhibitors } \\
\hline HbAlc (\%) & 298 & $8.5(1.5)$ & $7.7(1.2)$ & $-0.8(1.5)$ & $<0.001$ \\
\hline Body weight $(\mathrm{kg})$ & 68 & $95.9(19.2)$ & $93.4(18.3)$ & $-2.5(3.7)$ & $<0.001$ \\
\hline Systolic blood pressure $(\mathrm{mmHg})$ & 128 & $138.5(18.2)$ & $136.2(16.4)$ & $-2.3(16.8)$ & 0.227 \\
\hline
\end{tabular}

Note: Data are presented as mean (SD). Bold text indicate that the effect is significant.

Abbreviations: DPP-4, dipeptidyl peptidase-4; ID, index date; SD, standard deviation; HbAlc, glycated hemoglobin.

Diabetes, Metabolic Syndrome and Obesity: Targets and Therapy

\section{Publish your work in this journal}

Diabetes, Metabolic Syndrome and Obesity: Targets and Therapy is an international, peer-reviewed open-access journal committed to the rapid publication of the latest laboratory and clinical findings in the fields of diabetes, metabolic syndrome and obesity research. Original research, review, case reports, hypothesis formation, expert opinion and commentaries are all considered for publication. The manuscript management system is completely online and includes a very quick and fair peer-review system, which is all easy to use. Visit $\mathrm{http}: / / \mathrm{www}$. dovepress.com/testimonials.php to read real quotes from published authors. 